\title{
The Effect of Group Games on Children's Subsequent Impressions of Sketch Tasks and on their Design Outcomes
}

\author{
Rodrigo FERNANDES* and Toshimasa YAMANAKA** \\ * Graduate School of Comprehensive Human Sciences, University of Tsukuba, 1-1-1 Tennodai, Tsukuba-shi, Ibaraki 305-8577, Japan \\ ** University of Tsukuba, 1-1-1 Tennodai, Tsukuba-shi, Ibaraki 305-8577, Japan
}

\begin{abstract}
Co-designing with children is a recent challenge to the development of new products. Children and designers can express ideas through rough drawings, also called "sketches", but, while drawings are common activities, children can also display lack of confidence or engagement during this task. To motivate children before creating sketches, we considered the administration of group games. This paper tested the effects of different group games on participants' impressions and outcomes in subsequent design sketch tasks. Two studies were performed. In study 1, higher game difficulty was associated with negative impressions and less detailed drawings. By controlling difficulty, in study 2 we found that games positively affected children's confidence with their sketches, which indicated to affect design submissions. Results indicated an immediate effect of games on children's design sketch impressions and outcomes. If negative associations are properly controlled, games can be viable motivators for co-design tasks with children.
\end{abstract}

Keywords: Play, Motivation, Co-design

\section{INTRODUCTION}

Nowadays, for successfully developing new products, it is important to actively involve the user in all process stages. Named "Participatory design" or "Co-design", throughout this practice, developers can learn how a user feels toward certain products, understanding their issues and desires. To adequately integrate users, developers must consider questions such as their motivations, knowledge, or ideal involvement levels [1,2].

While successful practices of co-design have been performed in the last decades, only recently developers have been aiming to integrate children in the design process [3,4]. Among challenges, Guha et al. [5] pointed children's different communication strategies. For better working with children, dedicated tools and approaches must be developed.

One common point between adult designers and children is that both utilize drawings as communication tools [6]. Designers often utilize rough freehand drawings, also called "sketches", to initially communicate product ideas and features [7]. Children, on the other hand, are natural visual thinkers, displaying joy when drawing to express ideas and feelings $[8,9]$. Considering this connection, can we utilize sketches as a common communication tool between children and designers?

In middle childhood (6 to $12 \mathrm{y} / \mathrm{o}$ ), around the same age when drawn pieces start to get sufficiently developed to transmit concrete ideas, children also begin to become more self-aware about their drawing abilities, often comparing themselves with their peers [10]. When feeling that their drawings are not as good as their classmate's, children get inhibited and can lose confidence to share them. Therefore, properly motivating and disinhibiting children with their drawings is vital for their integration in co-design tasks.

As a motivating approach, "play" is a primary affective activity which facilitates children's engagement [11]. At middle childhood, it is expected that children will become more engaged with ta task when considering it more fun [12]. Different positive game effects on children's sociability, such as disinhibition, are being discovered through play-related studies [13,14].

In this paper, we hypothesized that game activities can be utilized for better engaging children on subsequent design tasks, affecting both the way they perceive and perform in these activities. Basing on that, two studies were performed to understand how previous game activities affects the way children, aged 6 to 12, perceived and performed in free-hand design sketch tasks.

In study 1, we tested how children in two different game groups which varied in difficulty, as well as children in a third control group who did not play any game, differently sketched new toy ideas and reported their impressions during a co-design activity. It was expected that children who played the easier group game would display higher satisfaction and performance with the design task. 
In study 2, we further observed how children who played a group game, when compared with children who did not, perceived and performed in a subsequent design sketch task. Working with a design competition context, it was expected that participants of the game group would perceive the design task more positively and would be more motivated to join the competition.

In both studies, we hypothesized that positive game experiences would contribute to the children's associated impressions, increasing their engagement and motivation with the sketch tasks. Given positive results, we expect to expand the current views of play benefits on children's impressions and to utilize games as suitable approaches to integrate children in different co-design processes.

\section{RELATED LITERATURE}

\subsection{Game effects on children's impressions}

Known as the work of children, play is a "primary affective motivational" activity which facilitates the development of different skills [11]. For the design of new play tools and games, a supporting view entitled "Design for Interactivity", advocates that products should facilitate interactions between people [15]. In the case of children, new toys and games should become more focused on promoting interactions between peers $[13,16,17]$.

Parallelly, research under the name of "Social game studies" have shown how different game elements positively engage children and affect their sociability [18]. For example, Hendrix et al [14] observed how the designation of roles in group games facilitated children's social interactions. Creighton \& Szymkowiak [19] observed how different exposures of cooperative and competitive games affected children's behavior.

One possible explanation for the positive relation between play and children's development is that playing affects their associated impression of different activities, making certain tasks more interesting or pleasurable. Focused on understanding how affection and impressions molds decisions, Kansei Science is a Japanese field which can connect game effects on children's impressions.

According to Nagamachi and Schütte [20], Kansei is the individual subjective impression from a certain artifact, environment or situation using all the senses of sight, hearing, feeling, smell, taste, recognition and balance. This view is Aligned with Montessori theories [21], which state that children are strongly dependent in their sensory channels to learn and explore the world. During play, through usage of senses, children's affective impressions can also contribute to their development.
Considering sensory exploration and the advancement of multimedia technology, modern play tools, entitled "interactive" or "smart" toys, utilize a series of sensors and actuators to provide adaptative sensory feedback for children [22]. Interactive toys can adapt to children's play patterns by increasing or decreasing the difficulty level of a game, and can provide different sensory interactions through electronic lights, sounds, or vibrations [23].

Based on the concept of sensory exploration through interactive games, Malinverni and Pares [18] linked usage of body movement with children's group impressions. In this study, participants played two different versions of a same team game, one computer-based, and another using body movements. According to the study, children who played the full body game version achieved better game scores and had more positive impressions of their group members.

Also Focused on multi-sensory effects, an experimental study reported that different exposures to the stimuli of sound, touch and taste differently affected the way children drew themselves in a self-portrait activity [9]. According to the study, the taste stimuli was the most pleasurable and was significantly related with richer self-portraits. Different sensory experiences were associated with perceived joy, which affected children's self-impressions.

These studies lead us to believe that different sensory stimuli associated with play exploration can also affect children's impressions and displayed behavior in subsequent activities. Being a pleasurable activity, play can positively motivate and encourage children on subsequent co-design activities, such as sketches.

\subsection{Co-design with children}

To integrate children in co-design activities, different studies established workshops to develop products, observing children's different group behaviors and design outcomes $[5,24,25]$. In these workshops, considerations were made regarding children's natural behaviors, their proper cooperation, and the outcome evaluation.

During a collaborative design study with children, Mona et al. [5], noticed that young children mostly struggled to add contributions to their peers' ideas. Since they are still developing social notions, it is often difficult for children to change established ideas and reach team consensus. Based on this, the researchers proposed a way for designing with children where ideas are individually developed through rough sketches and combined in later stages. By observing children in co-design situations, Mechelen [24] pointed the most usual obstacles for group performance to be: lack of motivation, diligence, and confidence. 
For evaluating the quality of children's drawings, it is important to avoid subjective bias and focus on objective elements. Following objective criteria, Mochizuke et al. [25] evaluated outcomes of a wood education workshop with children aged 5 to $6 \mathrm{y} / \mathrm{o}$ through the measurement of specific elements of drawing: number of colors, Number of items, and paper area utilization. By observing differences in children's design outcomes, we can understand the effect of previous game experiences.

\subsection{Research with children}

When performing research with children, there is a challenge to properly collect and analyze their different feedback. Traditionally, instruments that measure emotional responses rely either on psychological reports or physiological reactions [26]. Since children can be sensitive to physiological measurements, most of the related studies utilize observations, interviews or selfassessment reports.

When designing self-report tools for children, it is important to consider their communication skills. Working with children, Bell [27] stated that for providing optimal responses, children must: (1) understand the words and the sentences that form the question statement; (2) associate the question statement with an experience of their own to retrieve the required information; (3) understand that the questionnaire is asking them to make a judgment of their experience against the question statement; and (4) be provided with an effective method to communicate the judgement made in step 3 .

Due to verbal limitations, visual scales are often friendlier and preferred with children [26]. Another important point on interviewing children until the age of 12 is that they tend to have a strong acquiescence response bias, usually responding positively, irrespective of the question or of what they think about it [28].

Based on these notations, Halls et al. [25] developed an emotion-based scale tool with only positive expressions, called the "Smiley Face Likert Scale". After applying this tool, the researchers found that children selected a wider range of answers. A combination of visual scales with carefully designed questions can be suitable to evaluate children's impressions.

\section{STUDY 1: Game Difficulty on Children's Impres- sions and Design Outcomes}

Study 1 aimed to observe how different group games affect children's impressions and outcomes in a subsequent design sketch task. In this study, we tested two version of an interactive game, which varied in difficulty level and sensory feedback. To observe if both games were positive for children's design task impressions and outcomes, a third control group did not play the games. Designed sketches and task impressions reports were collected for analysis.

\subsection{Methods}

\subsubsection{Participants}

For this study, we relied on the participation of primary and junior students of an international school in Tsukuba city, Japan. 36 multinational students aged 6 to $16(M=9.58, S D=2.53)$, grade 2 to 9,24 males and 12 females, were divided in 12 multi-age teams of four children. We combined participants from different grades to ensure neutral relationships.

Before starting this project, we obtained approval from the Ethics committee of the University of Tsukuba Art \& Design Graduate school. We also requested authorization from the school headmasters and participant's guardians. A letter explaining the general purpose of the research and a consent form was sent to the guardians. Participants were also given explanation of the study procedures. Furthermore, participation was voluntary, and children were constantly reassured that, if feeling unwell or with any discomfort, they could interrupt the task at any time.

\subsubsection{Game stimuli and group conditions}

As the game stimuli of study 1, we utilized the "Hikari Tsumiki 2.0" [29], a set of interactive building blocks which can be combined to create tangible circuit structures. Observable in Figure 1, the set contains blocks with electronic lights, sounds, and rotary motors that can be activated by switches, movement, light, and sound sensors.

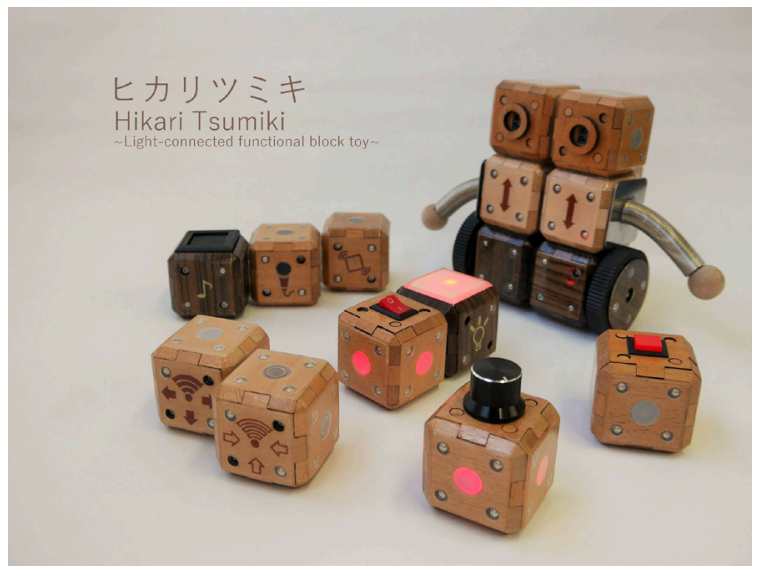

Figure 1: Hikari Tsumiki block 2.0.

Each block has a different interactive sensor, which can be rearranged to create circuits. 
Using different blocks of the Hikari Tsumiki 2.0 set, two game challenges were designed as group conditions:

- Easy Game Group (EG): Participants assembled circuits using the Hikari "light" and "sound" blocks.

This activity was easier.

- Difficult Game Group (DG): Participants assembled circuits using the Hikari "motor" blocks. The blocks were not facilitated with blinking lights and the task was more difficult."

To observe if both game conditions were positive for the subsequent design task, participants in a third control group, called "No Game Group" (NG), did not play the games before the design task.

\subsubsection{Design task: creating "sketches" of a new toy}

For the design task of this study, participants were invited to create a new toy. By showing examples, the researcher explained that toy the creation could be initially performed through rough drawings, also called "sketches", which can communicate ideas.

Participants would then proceed to individual desks, each provided with one A3 paper, a graphite pencil, eraser, and a 24-color pencil set. With these materials, participants had 10 minutes to individually sketch their ideas for a new toy and then discussed their ideas with the group for more 10 minutes. Shown in Figure 2, children's sketches were collected to be later analyzed.

For analyzing differences between children's drawings, we based on Mochizuki et al. [22] objective drawing evaluation model. Three elements were considered:

(1) Number of colors: Asides from black, how many colors were used.

(2) Number of items: together with the main object, text description, background, and accessory objects were counted in the composition.

(3) Number of ideas: How many different toy inventions children created.

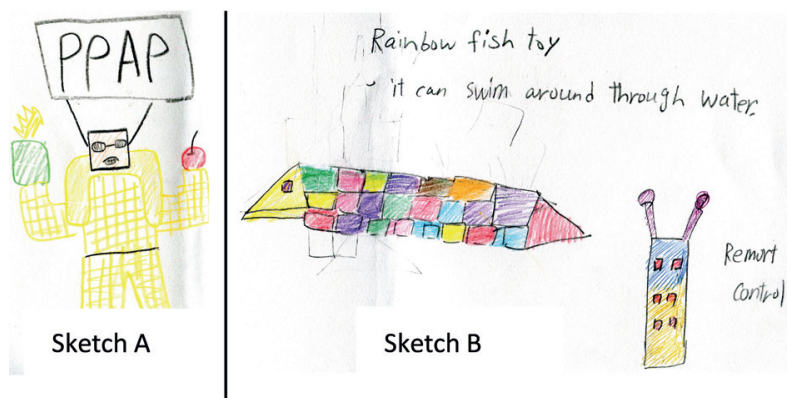

Figure 2: Two Samples of the collected sketches. Sketch A has four colors, one item, and one idea, while sketch B has ten colors, four items and one idea.

\subsubsection{Task impressions analysis}

After completing the game and the design task, participants were asked to fill a survey reporting their impressions of the task. Based on the Smiley Face Likert Self-report scale [28], the survey had 10 questions presented in visual 5-point scales. The report questions were averaged in three domains: Satisfaction with tasks; Group satisfaction; and task difficulty. Sample questions can be seen in Figure 3 below.

\subsubsection{Study procedure}

In this study, 12 groups of four children separately gathered to perform the game challenges and design tasks. sessions initiated with a 5-minutes video about "interactive toys", inviting participants afterwards to create a new toy. After this introduction, if participants were in the EG or the DG group, they would play their respective game challenges for 20 minutes. Participants in the NG group condition skipped the game challenge.

After the game challenge, participants proceeded to individual desks and would have 10 minutes to individually "sketch", or roughly draw their ideas for a new toy. After finishing the sketches, participants discussed their ideas with group members self-reported their design task impressions. Developed sketches and impression reports were collected. The procedure flowchart of this study can be observed in Figure 4 below.

1. How fun was the activity you had now?

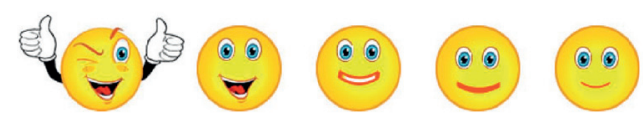

2. How happy are you with your team?

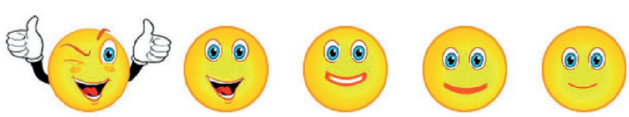

Figure 3: Adaptation of the Smiley Face Likert Scale [28]. From left to right, the scale decreases in happiness intensity, but the last icon is still interpreted as "happy".

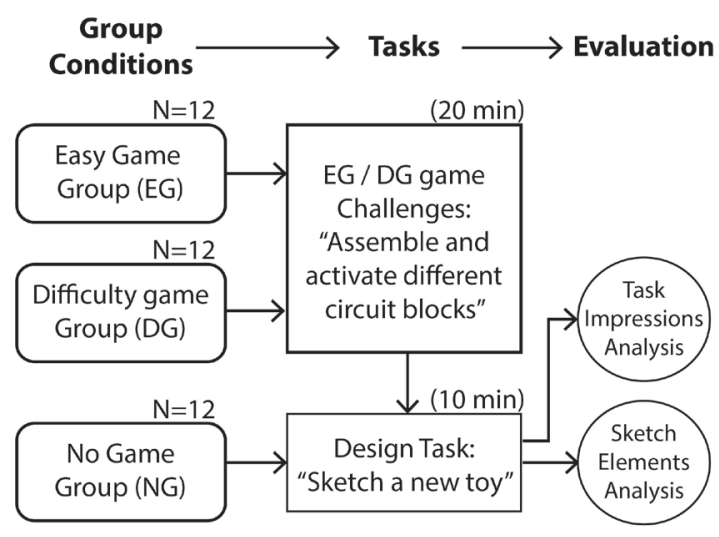

Figure 4: Procedure flowchart of Study 1. 


\subsection{Results Study 1}

We initiated the analysis by observing participants' reported impressions according to their group conditions. We proceeded by evaluating differences in the design sketch outcomes according to the group conditions and participants' reported impressions.

\subsubsection{Reported impressions by group conditions}

Non-parametric Kruskall-Wallis tests were conducted to rank the group conditions effects on three dimensions of the design task impressions: (1) task easiness; (2) task satisfaction; and (3) group satisfaction (Fig. 5).

There was a statistically significant difference between task easiness by the different group conditions $(\mathrm{H}(2)=$ 8.482, $\mathrm{p}=0.014$ ), with a Mean Rank of 19 for the EG group, 09 for he DG group, and 19 for the NG group. With the DG group participating in a more difficult game challenge but performing the same design task as both other groups, this result indicates that previous game conditions led the DG group to associate the design task as more difficult. The difference between the EG and NG groups, however, was not visible, with an easy game experience not necessarily facilitating the design task.

Although not statistically significant, a similar trend was observed on task satisfaction by group conditions $(\mathrm{H}(2)=4.08, \mathrm{p}=0.12$ : Mean Rank $\mathrm{EG}=19, \mathrm{DG}=11$, $\mathrm{NG}=16)$ and group satisfaction by group condition $(\mathrm{H}(2)=1.82, \mathrm{p}=0.4$ : Mean Rank $\mathrm{EG}=18, \mathrm{AG}=13, \mathrm{NG}=16)$.

Participants from the DG group reported less satisfaction with the task and with the group. Also, with a significant correlation between task "easiness" and "satisfaction" $\left(\mathrm{r}_{\mathrm{s}}=.53, \mathrm{p}=.001\right)$, as well as between "Task" and "Group" Satisfaction $\left(\mathrm{r}_{\mathrm{s}}=.80, \mathrm{p}=.001\right)$, we assume a close relationship between game difficulty and these reported impressions. Higher difficulty may have distressed overall impressions of the design task.

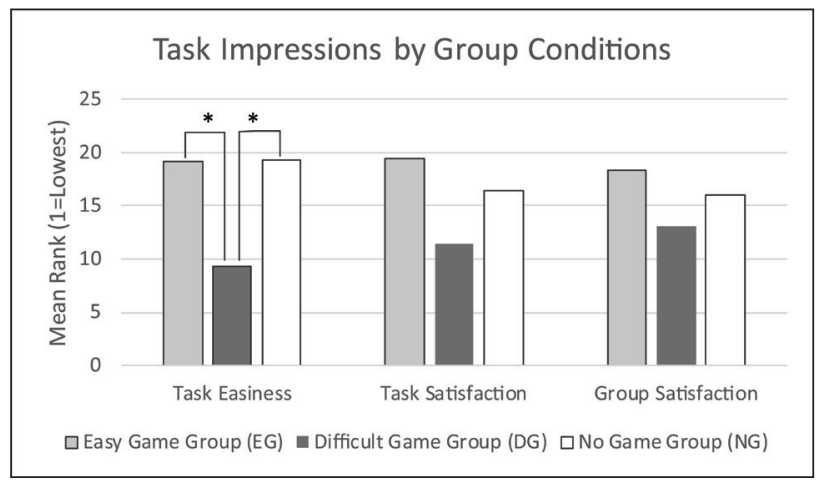

Figure 5: Rank of task impressions by group conditions. * $\mathrm{p}<.05$. A more difficult previous game experience negatively affected the impressions participants had of the subsequent task, but an easier game experience did not indicate significant effects.

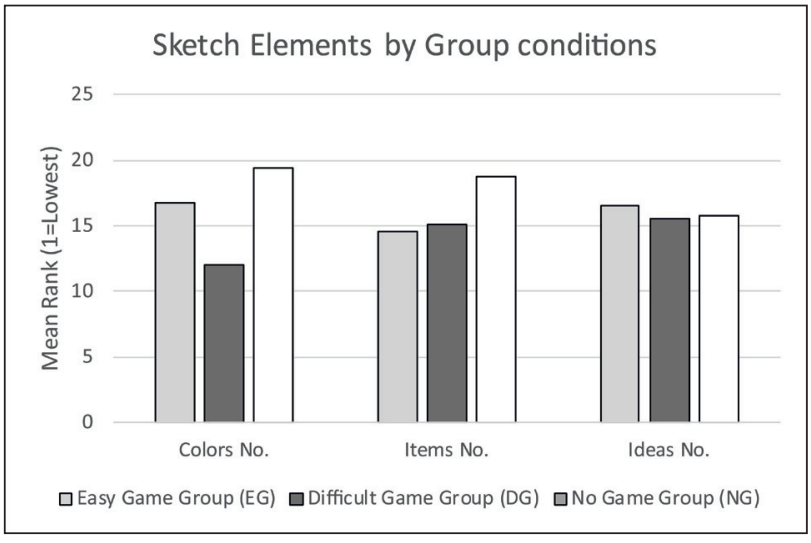

Figure 6: Rank of sketch elements by group conditions. Participants in the EG and DG groups indicated to utilize less colors and items than participants in the NG group condition.

\subsubsection{Design sketch outcomes by group conditions}

Seen in Figure 6, non-parametric Kruskall-Wallis tests were conducted to rank the effects of both group conditions on three sketch elements: (1) Number of colors; (2) Number of items; and (3) number of ideas.

In all three elements, there were no statistically significant differences. However, through these evaluations, participants in both game groups conditions were found to have designed less elements in their sketches than participants in the NG Condition. For example, there was a subtle difference in sketches colors by different group conditions $(\mathrm{H}(2)=3.50$, $\mathrm{p}=0.17$ ), with a Mean Rank of 17 for the EG group, 12 for the DG group, and 19 for the NG group. A similar pattern was present in both number of items and number of ideas. Between game groups, participants in the EG group indicated to have drawn more elements in their sketches.

\subsubsection{Design sketch outcomes by reported impressions}

We further normalized the design score by averaging them into a single unified item entitled "Design sketch quality". To test if the reported impressions could have influenced the overall sketch quality, a simple linear regression was calculated.

In Design sketch quality by task easiness, a significant equation was found $(F(1,29)=5.03, p=.03)$, with an $R^{2}$ of .147 indicating a small size effect. Participants' design score is equal to $1.30+0.28$ (task easiness) points when score is measured in a 5-Point scale. This result indicates that the more difficulty the design task was perceived, the less elements were found in the sketches. Effects of "task" and "group" satisfaction reports were not significant in the design sketch evaluations. 


\subsection{Discussion study 1}

In study 1, we observed if playing different group games would affect children's impressions and outcomes in a subsequent design task.

Among participants' reported task impressions by group conditions, we found a significant difference between groups regarding "task easiness" impressions, with participants in the DG group reporting design tasks to be more difficult, but with no differences observed between the "Easy Game" and "No Game" group conditions. This led us to believe that, more than facilitate, the game potentially distressed participants impressions of the design activity. Similar less noticeable effects were also noticed in task and group satisfaction, indicating a close relationship.

Regarding design outcomes, only a small variance was noted in the design sketches, with none of them being significantly related with the group conditions. Overall, participants in the DG group drew less elements when sketching their toy ideas, while participants in the NG group tended to elaborate more. Additionally, through a linear regression, we found that participants who considered the design task as easier were more likely to elaborate their sketches.

Overall, Participants who played the easy game did not indicate to perform or perceive the design task more positively. On the other hand, participants who played the difficulty game challenge indicated to have prejudiced performance and impressions during the design task.

Three considerations were made regarding the lack of effects according to the group conditions: (1) the game challenges were too long and complex, possibly tiring participant's before the design task; (2) many participants did not display high engagement or motivation with the design task; and (3), the allocated 10 minutes for sketching a new toy idea was too short, with most participants requesting more time to develop their ideas. These matters were considered for the design of study 2 , where we further observed the effects of games in children's task impressions and performance.

\section{STUDY 2: Game Effects on Children's Confidence Level and on their Design Submissions.}

In study 1, we compared the effect of playing two variations of a game before sketching a new toy idea. In that study, some possible game effects on participants' impressions were left unobserved. For example, questions about children's impressions of their own design outcomes, which could be a good way for measuring their confidence levels, were not made. Furthermore, considering that there were no negative associations (such as frustrations due to high difficulty or fatigue with time), we needed to observe if group games could be positive task motivators.

Working on these points, we defined the following goals for study 2: (1) simplify the game challege, making it shorter and with less restrictions; (2) Give more time for participants to develop their sketches; and (3), observe children's design outcome in a more close-to-reality context, involving them into a competition with clear goals and rewards.

\subsection{Methods}

\subsubsection{Participants and ethical considerations}

Six months after participating in study 1, primary school students of the same international school in Tsukuba city joined study 2.21 participants aged 6 to 10 $\mathrm{y} / \mathrm{o}(\mathrm{M}=7.94, \mathrm{SD}=1.30)$, grade 2 to 4,13 males and 8 females, were divided in six same-grade, mixed gender groups. Group size varied between three to four children, according to the classroom size. The ethical guidelines of study 1 were also applied in this study.

\subsubsection{Game stimuli and group conditions}

For study 2, we have selected a set of 105 building blocks as a game challenge. Participants had 21 to 22 pieces each and the goal was to connect them into a unique structure, giving opportunity for everyone in a group to collaborate. Participants had 10 minutes to conclude the task and the goal was achieved if all the pieces were connected. We opted to work with this game for being a simpler free-play constructive toy which did not require complex rules.

Considering the simplicity of the game stimuli, two group conditions were created: The Team Game group (TG), where participants played a team game before performing individual design tasks, $\mathrm{N}=09$; and the No Game group (NG), where participants performed the design task without playing the game, $\mathrm{N}=12$.

\subsubsection{Design task: creating a new communication tool}

For the design task of study 2, we took opportunity of an existing children-dedicated design competition at the "interaction Design with Children Conference - IDC 2018" [30]. in this competition, participants needed to create and submit a new product or invention idea that could improve communications between children.

Following competition guidelines, participants needed to develop a sketch and write a simple explanation of their creation attending three questions: (1) "What is 


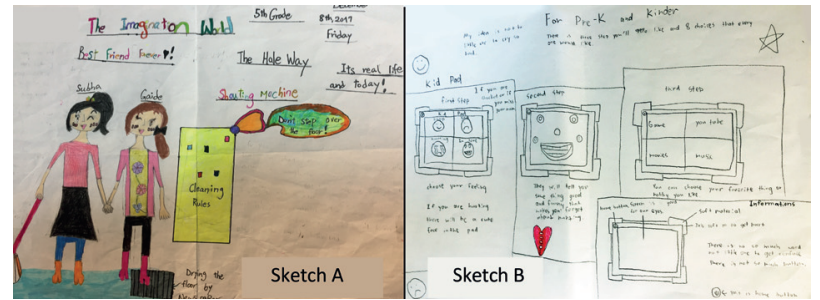

Figure 7: Examples of submitted sketches. Invention title, drawings and descriptions are observable.

the name of your creation?"; (2) "What does it do?"; and (3) "How do You use it?". Being our main parameter for quality evaluation, if these questions were attended, the submission would be considered successful.

Like in study 1, after receiving instructions, the participants proceed to individual desks, each provided with one A3 paper, a graphite pencil, eraser, and a 24-color pencil set. With these materials, participants had 20 minutes to individually "sketch" their ideas, being allowed to discuss them during the design task.

While the sketch session took 20 minutes, participants were given a 1-week deadline to further improve their ideas before submission. Until the end of the deadline, final sketches and explanations were to be given to a responsible school staff member. Example of submitted sketches can be seen in Figure 7.

\subsubsection{Task impressions analysis}

After completing the design task, participants were asked to fill a survey reporting their impressions of the task. Also based on the Smiley Face Likert Self-report scale [28], the survey had 12 questions presented in visual 5 -point scales. This redesigned survey focused on the three domains present in study 1 (Task satisfaction, Task easiness, and group satisfaction), adding a fourth domain called "design confidence" (Q7. How good do you think your idea was?).

\subsubsection{Study procedure}

In study 2, we worked with two main groups: The No Game Group (NG), and the Team Game Group (TG). Six Study sessions were performed with children in groups of three to four members, according to the class size.

Participants in the TG group condition started by playing the "rolling ball structure game" for 10 minutes. Upon completion of the game goal, the participants received positive comments, were instructed to put the toy back In the box together and then initiated the design task. participants in the NG group condition started the design task without playing the game challenge.

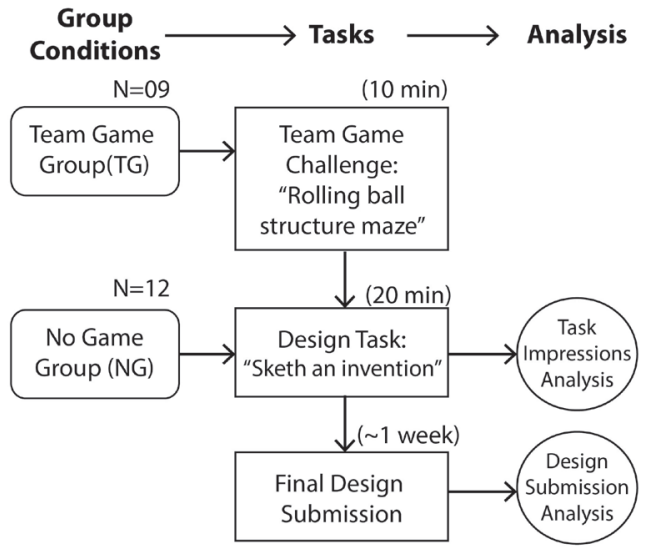

Figure 8: Procedure flowchart of Study 2

In the design task, participants listened explanation about the proposed design competition and were given 20 minutes to initially sketch ideas with the given material. After 20 minutes, Participants were interrupted to answer a survey about their task impressions and were told about the one-week deadline for submitting their ideas. Asides from giving more time to improve the quality, this period was meant to test participant's motivations with the task. The submitted ideas and task impressions reports were gathered for analysis. The process can be seen in Figure 8 .

\subsection{Results study 2}

We initiated study 2 analysis by observing participants reported impressions according to the group conditions. We proceeded by evaluating differences in the design submission according to the group conditions and the reported impressions.

\subsubsection{Task impressions by group conditions}

Wilcoxon Signed-Rank tests were conducted to compare the design task impressions of participants in the Team Game (TG) and the No Game (NG) Group conditions.

Observable in Figure 9, through this test, the reported design confidence of participants in the TG group

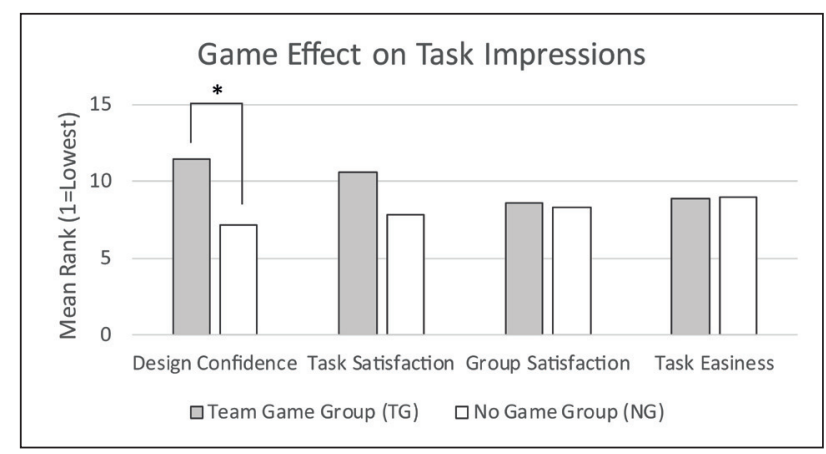

Figure 9: Game effect on Task Impressions. ${ }^{*} \mathrm{p}<.05$ Design confidence was significantly higher among participants in the Team Game Group condition. 
condition $(\mathrm{Mdn}=5)$ was significantly higher than participants in the $\mathrm{NG}$ Group $(\mathrm{Mdn}=4), \mathrm{Z}=1.92$, $p<.05$. This result indicates that participants who played the game before the design task had better impressions of their ideas. Although not statistically significant, there was also a similar trend on task satisfaction, with participants in TG group reporting higher task satisfaction than participants the NG Group. No differences were observed in either Group satisfaction or Task Easiness.

A Spearman's correlation test was run to assess the relationship between task impressions. There was a strong positive correlation between "Task satisfaction" and "design confidence" $\left(\mathrm{r}_{\mathrm{s}}=.62, \mathrm{p}=.007\right)$, indicating an association between fun and confidence, which could have been affected by the group conditions.

\subsubsection{Design submissions by task impressions}

Logistic regression analyses were performed to examine the relation between participant's reported impressions and the design Submission in two conditions: (1) submitted idea for the competition, and (2) did not submit. Four participants were excluded from these analyses for not properly answering the surveys.

Results pointed that "task" and "group" satisfaction", as well as "task easiness" had no significant effects in the design submissions. "Design confidence", on the other hand, was significantly related with design submission rate, $\mathrm{X}^{2}(1)=6.73, \mathrm{p}=.009$. In a five-point scale, only participants who evaluated their confidence higher than 4 points successfully submitted their designs.

According to Table 1, while no participant who rated their confidence below 5 points submitted their design to the competition $(\mathrm{N}=07,0 \%), 5$ participants who rated 5 points for their confidence $(\mathrm{N}=10,50 \%)$ were successful with their submissions.

\subsubsection{Design submissions by group conditions}

To observe if the group conditions affected the design submissions, we performed a contingency analysis between the group conditions ( $\mathrm{NG}, \mathrm{N}=12$ / $\mathrm{TG}, \mathrm{N}=9$ ) and the Design submission outcomes (submitted, $\mathrm{N}=5$ / Did not submit, $\mathrm{N}=16$ ).

Table 1: Submissions by reported Confidence

\begin{tabular}{|c|c|c|c|}
\hline $\begin{array}{c}\text { Quantity N } \\
\text { Percentage) }\end{array}$ & $\begin{array}{c}\text { Did not } \\
\text { Submit Design }\end{array}$ & $\begin{array}{c}\text { Submitted } \\
\text { Design }\end{array}$ & Total \\
\hline $\begin{array}{c}\text { Confidence in } \\
\text { Design = 1-4 }\end{array}$ & $7(41.18 \%)$ & $0(0 \%)$ & $7(41.18 \%)$ \\
\hline $\begin{array}{c}\text { Confidence in } \\
\text { Design = 5 }\end{array}$ & $5(29.41 \%)$ & $5(29.41 \%)$ & $10(58.82 \%)$ \\
\hline Total & $12(70.59 \%)$ & $5(29.41 \%)$ & $17(100 \%)$ \\
\hline
\end{tabular}

Table 2: Submissions by Game Groups

\begin{tabular}{|c|c|c|c|}
\hline $\begin{array}{c}\text { Quantity N } \\
\text { Percentage) }\end{array}$ & $\begin{array}{c}\text { Did not } \\
\text { Submit Design }\end{array}$ & $\begin{array}{c}\text { Submitted } \\
\text { Design }\end{array}$ & Total \\
\hline $\begin{array}{c}\text { No Game } \\
\text { Group (NG) }\end{array}$ & $12(57.14 \%)$ & $0(0 \%)$ & $12(57.14 \%)$ \\
\hline $\begin{array}{c}\text { Team Game } \\
\text { Group (TG) }\end{array}$ & $4(19.5 \%)$ & $5(23 \%)$ & $9(42.85 \%)$ \\
\hline Total & $16(76.19 \%)$ & $5(23.8 \%)$ & $21(100 \%)$ \\
\hline
\end{tabular}

According to Table 2, while no participant of the NG group submitted their design to the competition $(\mathrm{N}=12$, $0 \%), 5$ participants of the TG group $(\mathrm{N}=9,55.5 \%)$ successfully submitted it. Through Right-Tailed Fishers Exact Test of Independence, the relation between these variables was significant, $\mathrm{X}^{2}(1)=10.6, \mathrm{p}<.005$. This result indicates that Participants in the TG condition were more successful in submitting their designs for the competition.

\subsection{Discussion study 2}

In study 2 , we intended to further observe if playing a game would positively affect children's impressions of a subsequent design task. Furthermore, through their design submissions, we aimed to see how the reported impressions would affect their outcomes.

Among participants' reported impressions, "design confidence" indicated to strongly influence their motivation to join the competition. Both confidence reports and design submission rate indicated to be positively affected by the group conditions, as children of the TG Group reported higher satisfaction, design confidence, and were the only participants to submit their designs.

The reasons behind the game possibly affecting the design submission rate were not clear. It could be either or both: (1) an associated effect with higher satisfaction levels, indicating that the game might have made the participants more interested and motivated in the design task; or (2) an associated effect with confidence / self-esteem building, indicating that the game encouraged or aided children's self-perception of values.

Due to the study procedure, an alternate explanation is that the game may have acted as a reference point for the children's designs. Although the designs were not directly inspired by the "rolling ball structure maze" toy, playing a game might have influenced their solutions toward playful products. This relation between games and playful design elements can be considered in future studies.

A limitation factor of this study was that design outcomes could only be evaluated based on the submission guidelines instead of the same criteria of study 1 . 
Although attending to the competition guidelines, there are still open questions about the game effect in the design quality levels. For future studies, it would be interesting to see if higher confidence levels motivated by game activity can motivate children to develop and detail more ideas.

\section{MAIN CONSIDERATIONS}

In this paper, both studies tested the effect of previous game experiences on children's impressions and outcomes of subsequent design tasks. Observing the game effect in children's satisfaction with the task and the group, study 1 identified that children who had a more difficult game experience also had prejudiced impressions of the design task. By Controlling game difficulty and including "confidence" as an evaluation factor, study 2 found that previous game experience was directly related with increases in children's design confidence, which indicated to affect their final submissions.

Both studies found an immediate effect of game activities on the impressions and outcomes of design tasks. If negative associations such as "high difficulty" can be controlled, game experiences indicate to successfully increase children's confidence and engagement with subsequent tasks. Positively answering our initial hypothesis, we believe this effect happens because the impressions and engagement children display in game activities are associable with subsequent task impressions.

Among limitations of this paper, we consider that the found effects were restricted to the participant's individual level. In a group situation, such the case of many design tasks, we have yet to observe if these increases in confidence are positive to the task dynamics. Therefore, in following studies, the relationship between group games, self-confidence, and group behavior should be better explored.

Additionally, for further observing game effects on children's motivation and engagement, we should consider "arousal" as an independent dimension affected by play activities. With arousal being the feeling of energy or attention regarding an activity, assessments considering this dimension can go beyond "task satisfaction" evaluations. Considering these factors, we defined that future studies should combine children's reported impressions with their displayed group behavior, when challenged with a common goal.

Even at the individual level, our findings expand the current view of play benefits on children's impressions and behavior. Not limited to design sketch activities, we believe games can be suitable motivators for different group tasks. Considering that, we expect this study to contribute to the development of game applications as ice-breakers or motivators for subsequent group activities.

\section{REFERENCES}

1. Lee, Y.; Design Participation Tactics: the challenges and new roles for designers in the co-design process, Co-Design, 4(1), pp.31-50, 2008.

2. Smith, F., Jackson, C., and Greenhalgh, T.; Co-design and implementation research: challenges and solutions for ethics committees, BMC Medical Ethics, 16(78), pp.1-5, 2015.

3. Druin, A.; The role of children in the design of new technology, Behavior and Information Technology, 21(1), pp.1-25, 2002.

4. Xie, B., Druin, A., Fails, J., et al.; Connecting generations: developing co-design methods for older adults and children, Behaviour \& Information Technology, 31(4), pp.413-423, 2010.

5. Guha, M., Druin, A., Chipman, G., et al.; Mixing ideas: a new technique for working with young children as design partners, 3rd Interaction Design with Children Conference - IDC, Maryland, 2004.

6. Anning, A., and Ring, K.; Making sense of children's drawings, Open University Press, New York, p.124, 2004.

7. Cross, N.; Natural intelligence in design, Design Studies, 20(1), pp.25-39, 1999.

8. Farohki, M., and Hashemi, M.; The analysis of children's drawings: social, emotional, physical, and psychological aspects, Procedia - Social and Behavioral Sciences, 30, pp.2219-2224, 2011.

9. Chen, Y.-C., and Li, M.-L.; Study on drawing creation of children through multiple senses learning, 6th International Kansei Engineering and Emotion Research Conference - KEER, Leeds, 2016.

10. Vlach, H., and Carver, S.; The effects of observation coaching on children's graphic representation, Early Childhood Research and Practice, 10(1), 2008.

11. Lafreniere, P.; Children's play as a context for managing physiological arousal and learning emotion regulation, Psychological Topics, 22(2), pp.183-204, 2013.

12. Eleni, M.; Play theories: a contemporary review, Early Child Development and Care, 102(1), pp.91100, 2006.

13. Hart, S.; Inclusion, play, and empathy, Jessica Kingsley Publishers, London, p.350, 2015.

14. Hendrix, K., Herk, R. V., Verhaegh, J., and Markopoulos, P.; 
Increasing children's social competence through games: an exploratory study, 8th Interaction Design with Children Conference - IDC, Como, 2009.

15. Muto, T.; Design for children's creativity development: the seven perspectives, Kids Design Association Webpage, http://www.kidsdesign.jp/cat31/vol14/ index.html (accessed 2018.06.23). (in Japanese)

16. Hourcade, J.; Interaction design and children, HumanComputer Interaction, 1(4), pp.277-392, 2008.

17. Takahashi, I., Oki, M., Bourreau, B., et al.; FUTUREGYM: a gymnasium with interactive floor projection for children with special needs, International Journal of Child-Computer Interaction, 15, pp.37-47, 2018.

18. Malinverni, L., and Pares, N.; The medium matters: the impact of full-body interaction on the socioaffective aspects of collaboration, 14th Interaction Design with Children Conference - IDC, Medford, 2015.

19. Creighton, S., and Szymkowiak, A.; The effects of cooperative and competitive games on classroom interaction frequencies, Social and Behavioral Sciences, 140, pp.155-163, 2013.

20. Schütte, S.; Engineering emotional values: Kansei engineering in development, Linköpings Universitet Press, Linköpings, p.106, 2005.

21. Montessori, M.; The montessori method, Transaction Publishers, New Brunswick, p.376, 2001.

22. Cagiltay, P., Kara, N., and Cigdem, C.; Smart toy based learning. In book: Handbook of Research on Educational Communications and Technology Edition. Springer, 4th ed., 2014.

23. Adilon, J. S., Ferrer, J., and Parés, N.; A novel approach to interactive playgrounds: the interactive slide project, In; proceedings of the 8th Interaction Design with Children Conference - IDC, New York, US, pp.131-139, 2009.

24. Mechelen, M., Zaman, B., Laenen, A., and Abeele, V.; Challenging group dynamics in participatory design with children: lessons from social interdependence theory, 14th Interaction Design with Children Conference - IDC, Medford, 2015.

25. Mochizuki, Y., Tanaka, E., Tomisaki, E., et al.; Effects of Wood Education in a Nursery School with a focus on changes in children and caregiver's drawings, International Journal of Psychology and Behavioral Sciences, 3(6), pp.145-150, 2013.
26. Mamaghani, N. K., Mostowfi, S., and Khorram, M.; A comparative study of educational computer games by Kansei engineering (Premo) and fun toolkit, 6th International Kansei Engineering and Emotion Research Conference, Leeds, 2016.

27. Bell, A.; Designing and testing questionnaires for children, Journal of Research in Nursing, 12(5), pp.335-371, 2007.

28. Hall, L., Hume, C., and Tazzyman, S.; Five Degrees of happiness: effective smiley face likert scales for evaluating with children, 15th Interaction Design with Children Conference - IDC, Manchester, 2016.

29. Kawaguchi, I., and Yamanaka, T.; Hikari Tsumiki: Module toy for hardware education which visualize information using visible light, Annual Design Review of Japanese Society for the Science of Design, 22(1), pp.40-43, 2017. (in Japanese)

30. Interaction Design and Children Design Competition Website, http://idc-2018.org/research-design-competition/ (accessed 2018/06.23).

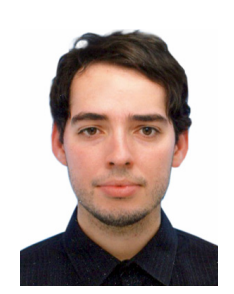

Rodrigo Queiroz Kuhni FERNANDES (Non-member) Rodrigo Fernandes is a PhD candidate at the Kansei Information Science Laboratory, Doctoral Program in Kansei, Behavioral and Brain Sciences, Graduate School of Comprehensive Human Sciences Department of the University of Tsukuba. His interests are children's Kansei, education, interaction design, toy design, and co-designining with children.

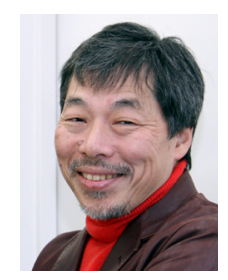

Toshimasa YAMANAKA (Member)

Toshimasa Yamanaka is a professor at the Kansei Information Science Laboratory, Masters and Doctoral Program in Kansei, Behavioral and Brain Sciences, Graduate School of Comprehensive Human Sciences Department of the University of Tsukuba. He is currently the Chair of the Masters and Doctoral Program in Kansei, Behavioral and Brain Sciences as well as the vice chair of the Graduate School of Comprehensive Human Sciences of the University of Tsukuba. 